\title{
Gordon conference clones
}

\section{Munich}

IN an attempt to counteract a sense of being second best to the United States in setting the trends in scientific research, a group of European researchers from a wide variety of disciplines is borrowing an idea that has proved quite successful in boosting US science. The group, led by such eminent researchers as the German ethologist Hubert Markl, head of the granting agency DFG (Deutsche Forschungsgemeinschaft), and physicist Sir William Mitchell of Clarendon Laboratory in Oxford, is trying to develop an array of European Research Conferences modelled on the renowned Gordon Conferences in the United States.

If the proponents get the 10 million ECU (about $\$ 7.7$ million) over five years that they are requesting from the European Communities (EC), they will organize as many as HEALTH AT WORK

\section{Exoneration for VDTs}

\section{Washington}

Pregnant women who use video display terminals (VDTs) in their work are no more likely to suffer miscarriages than women who do not, according to a report published last week (New England Journal of Medicine 324, 728; 14 March 1991).

The study, which was carried out by researchers at the National Institute for Occupational Safety and Health (NIOSH) in Cincinnati, Ohio, should allay fears raised by clusters of spontaneous abortions among women who have worked with VDTs. Several miscarriages, for example, were reported in 1988 among women who worked at USA Today in Arlington, Virginia.

The NIOSH scientists studied two groups of women telephone operators in eight states in the southeastern United States. One group consisted of directoryassistance operators who used VDTs, and the second group was composed of general telephone operators who did not. There was no increased risk of miscarriage among the VDT users; indeed, they had a slightly lower rate of miscarriage, although the difference was not statistically significant.

The results appear to rule out very-lowfrequency (15 kilohertz) electromagnetic fields as a risk factor in causing spontaneous abortions, as operators who used VDTs had measurably higher exposure to these fields than did the control group. The researchers noted, however, that the data say nothing about risks associated with exposure to extremely low frequency (in this case, 45-60 hertz) fields. The measured exposure levels to these fields were approximately the same for both groups of operators.
120 conferences a year by 1995 in five major fields: chemistry, physics, biosciences, geosciences and humanities.

The conferences, which will be overseen by the Strasbourg-based European Science Foundation (ESF) in conjunction with several European scientific societies, will in some cases merely continue a tradition of European cooperation established by scientific societies. The European Chemistry Society, for example, has been running pan-European meetings for many years. But the planned conferences would be broader in scientific scope and in their degree of international participation than any existing European programme.

Perhaps the most important innovation will be the attempt to include large numbers of young researchers from all regions of Europe in the conferences. By making EC money available for the conferences, it will be possible for groups in less-developed countries to send their junior members to international meetings.

A few meetings of this type have already been held by the ESF and have met with an overwhelming response. One meeting, on supramolecular chemistry, set to be held later this year under the chairmanship of French Nobel laureate Jean-Marie Lehn, has received 250 requests for information even before the first public announcement.

Like the Gordon Conferences, which have been held annually for 60 years, mostly in New England, the European conferences would bring together a varied group of researchers for five-day meetings on narrowly defined subjects. Most subjects would be addressed by a series of meetings to be held every other year. The organizers would allow ample time for recreation and socializing in order to encourage the free exchange of ideas.

And as at the Gordon Conferences, researchers attending the new meetings would be asked not to discuss the content of the meeting with outsiders. This measure would encourage the participants to discuss even 'half-baked ideas' as well as recent, unpublished results from their laboratories, says Josip Hendekovic, executive secretary of ESF. It is precisely this kind of unpressured exchange that has made the Gordon Conferences so successful.

Although European researchers have sometimes been invited to speak in the United States, they often feel that they are excluded from the process of choosing what will become the 'fashionable' fields of science.

Hendekovic and the other backers hope that the conferences will increase a sense of European identity, especially among young researchers. He sees a time coming by the year 2000 when the United States will draw even more strongly on European and

\section{Inquiry launched into ethical procedures}

\section{Paris \& Washington}

THE French health minister, Bruno Durieux, has ordered an inquiry into research carried out by Daniel Zagury, an AIDS researcher at the Pierre and Marie Curie University in Paris. Zagury's research on AIDS vaccines, in collaboration with scientists at the US National Cancer Institute, including Robert Gallo, is the subject of a recent article by John Crewdson, a Chicago Tribune reporter, suggesting that ethical procedures may not have been respected. Zagury says that he followed appropriate ethical procedures for research in France and that he was not subject to US guidelines because he was not actually using materials from US laboratories.

The inquiry will initially focus on Zagury's work at the Saint-Antoine hospital in Paris, where two trials of a candidate AIDS vaccine (based on deactivated gp 120 protein) have been carried out on volunteers: one on seronegative medical interns, the second on patients suffering from AIDS. There is also controversy surrounding clinical trials carried out in Zaire by Zagury, but it is unlikely that these will be the object of the same French health ministry inquiry.

The US National Institutes of Health halted all collaboration with Zagury in early February and is conducting its own investigation into the case.

Peter Coles \& Christopher Anderson

Japanese talent in science and engineering to fill a growing 'talent gap'. In order to prevent the top European researchers of tomorrow from migrating to the United States, Hendekovic says, Europe needs to start now to convince young people that they would not be "missing the boat" if they stayed in Europe.

If approved by the EC, the conferences will bring in primarily - but not exclusively - European participants, including some from countries that are not EC members. Switzerland, Sweden and other European Free Trade Association (EFTA) members, several of which have bilateral scientific cooperation agreements with EC, would participate, as well as ESF members such as Hungary, Yugoslavia and Turkey.

According to Hendekovic, optimists say that the EC will reach an agreement this summer on the conferences, which are included in line 6 of the budget for the third Framework Programme in the section on "human capital and mobility".

If the EC agrees this summer, the conferences could start in spring 1992. But delaying the decision, Hendekovic says, would make it "very, very difficult" to get the conferences started on the schedule ESF would like.

Steven Dickman 